\title{
Photocatalytic Activity in Phenol Removal of Water from Graphite and Graphene Oxides: Effect of Degassing and Chemical Oxidation in the Synthesis Process
}

\author{
Karina Bustos-Ramirez, ${ }^{1,2,3}$ Carlos Eduardo Barrera-Diaz, ${ }^{1}$ Miguel De Icaza, ${ }^{3}$ \\ Ana Laura Martínez-Hernández, ${ }^{2,3}$ and Carlos Velasco-Santos ${ }^{2,3}$ \\ ${ }^{1}$ Centro Conjunto de Investigación en Química Sustentable, Universidad Autónoma del Estado de México and \\ Universidad Nacional Autónoma de México, Km 12 de la Carretera Toluca-Atlacomulco, San Cayetano, 50200 Toluca, MEX, Mexico \\ ${ }^{2}$ División de Estudios de Posgrado e Investigación, Instituto Tecnológico de Querétaro, \\ Avenida Tecnológico s/n Esquina con Mariano Escobedo, Colonia Centro Histórico, 76000 Querétaro, DF, Mexico \\ ${ }^{3}$ Centro de Física Aplicada y Tecnología Avanzada, Universidad Nacional Autónoma de México, \\ Boulevard Juriquilla 3001, 76230 Querétaro, DF, Mexico \\ Correspondence should be addressed to Carlos Velasco-Santos; cylaura@gmail.com
}

Received 14 October 2014; Revised 19 March 2015; Accepted 20 March 2015

Academic Editor: Nurettin Sahiner

Copyright (C) 2015 Karina Bustos-Ramirez et al. This is an open access article distributed under the Creative Commons Attribution License, which permits unrestricted use, distribution, and reproduction in any medium, provided the original work is properly cited.

\begin{abstract}
Developing new materials or modifying the existing ones is an amply field studied in the world of research. Due to its outstanding physical and chemical properties, graphene is attractive material for new applications. The methodologies for obtaining graphene are diverse and have changed over time. Graphene oxide is a versatile form of graphene, due to the presence of oxygenated functional groups. Chemical oxidation of graphite and exfoliation by ultrasonic waves is one of the preferred methods to obtain graphene oxide; chemical oxidation time and the degassing effect in the ultrasonic bath are parameters that play an important role in the features and properties of graphene oxide. Thus, in this study, the conventional times used for the oxidation of graphite and degassing in an ultrasonic bath to obtain graphene oxide were modified. The structural changes in the carbon materials were evaluated based on their photocatalytic activity in the removal of an organic pollutant in water (removing up to $38 \%$ of phenol). The band gaps of the graphitic materials were obtained by UV-vis obtaining a value range of 1.5-4.7 eV and the structure and morphology of the carbon materials were characterized by infrared and Raman spectroscopies and transmission electron microscopy, respectively.
\end{abstract}

\section{Introduction}

Graphite oxide (GO) is a graphite derivative which contains covalently attached oxygen-containing groups on its layers. The oxygen groups are often hydroxyl, epoxy, and carboxyl, which are embedded within the carbon layers and are generated in the course of GO synthesis by strong chemical oxidation $[1,2]$. As GO contains a high concentration of exposed oxygen-containing functional groups, it is considered to be a multifunctional organic network which can be applied in a wide range of chemical transformations, most commonly with the $\mathrm{C}-\mathrm{OH}[3,4], \mathrm{OH}[5,6]$, and epoxy groups [7-9].

Nowadays, there are three major methods used to synthesize GO, that is, the Brodie, Staudenmaier, and Hummers methods $[10,11]$. The level of oxidation can be varied on the basis of the method, the reaction conditions, and the precursor graphite used. One of these methods, the Hummers method, is generally considered the best $[12,13]$, and the majority of researchers have followed it. Also, in 2008, a modification of the Hummers method improved the oxidation degree and thus the method increases its utility [14].

Graphene oxide (GEO) can be obtained from GO under conditions of thermic or ultrasonic exfoliation, which leads to individual graphene oxide sheets. The formation of oxygenated functional groups in GO makes them easier to exfoliate into monolayers of GEO by stirring or mild sonication. To obtain fewer sheets, the sonication method is used and 
commonly takes place in an ultrasonic bath operated at $40 \mathrm{kHz}[15,16]$ or $50 \mathrm{kHz}[17,18]$.

It is already well known that, chemically, GO and GEO have similar structures. Both possess stacked structures with chemical functionality on their basal planes and at their edges. The difference between them is the number of stacked layers. Both materials GO $[19,20]$ and GEO [21] have photocatalytic activity, shown by water splitting and hydrogen production, and can reduce resazurin into resorufin [22]. Also, both carbon structures can be doped with different materials $[23,24]$ or atoms [25] to improve their performance as photocatalysts.

Additionally, reduced graphene oxide (RGO) modified with different compounds has been successful as a photocatalytic material in the removal of heavy metals [26, 27] and organic compounds [28]. However, the photocatalytic activity of unmodified GO and GEO has not been studied in the removal of organic compounds in water. Within the new materials to remove phenol in water are Nano $\mathrm{ZnO}$ [29], $\mathrm{CeO}_{2} / \mathrm{MgAl}$ layered double hydroxides [30], and $\mathrm{TiO}_{2}$ rGO nanocomposites [31]; in these researches, materials get removed among 50\% and $90 \%$ of the phenol concentration, considering different concentrations in each study; these new materials are efficient in the removal of phenol by heterogeneous photocatalysis but long time of reaction is required and in some cases the addition of oxygen/air to accelerate the photocatalytic process; also, it is needed to work in the electron-hole recombination. The advantage to exploit the possibilities to use GO and GEO as photocatalyst is that oxygen groups in the surface that could contribute to these parameters can be subtracted generating an interesting field, related with doped and nondoped graphitic materials in photocatalysis. Thus, it is important to verify the photocatalytic activity of both of these carbon unmodified materials for the removal of organic compounds in water, considering the different changes that carbon structures undergo during the synthesis process and the effects on their structures.

In the synthesis of GO and GEO, the sonication process and the oxidation time are key factors; however, only a few studies have investigated modifications to these parameters to obtain the optimal conditions for a good chemical functionalization [32-34]. Oxidation time changes the number of functional groups and carbon hybridized $\mathrm{sp}^{2}$ in both materials and the chemical effects of ultrasound derived from acoustic cavitation are relevant in this kind of process. The effects of cavitation are the basis of sonochemistry and are extremely effective in liquid degassing [35, 36]. Thus, in this study, changes in the carbon structure (GO and GEO) produced by degassing and oxidation time were analyzed. Additionally, the photocatalytic activity was demonstrated by the elimination of phenol in water. Transmission electron microscopy was used to examine the topography of the materials, FT-IR was applied to identify the functional groups in the oxidized samples, Raman spectroscopy was utilized to identify the hybridization of carbon samples and UV-vis spectroscopy, and Tauc's method was used to obtain the band gap of the graphene oxide materials.

\section{Material and Methods}

2.1. Synthesis of Graphite and Graphene Oxides. Graphite oxide (GO) was synthesized from graphite by an established method [14, 37]; however, the reaction time was modified to determine the influence of this parameter on the oxidation process and therefore on the structure of GO and then on the bang gap results and photocatalytic activity. The reactants used were graphite (Electron Microscopy Sciences, number 70230$)$, sulfuric acid $\left(\mathrm{H}_{2} \mathrm{SO}_{4}\right.$, Baker, 98\%), potassium permanganate $\left(\mathrm{KMnO}_{4}\right.$, Merck), hydrogen peroxide $\left(\mathrm{H}_{2} \mathrm{O}_{2}\right.$, Baker, 30\%), and distilled water $\left(\mathrm{H}_{2} \mathrm{O}\right)$.

$\mathrm{H}_{2} \mathrm{SO}_{4}(46 \mathrm{~mL})$ was added into the reaction flask maintained at $0^{\circ} \mathrm{C}\left( \pm 2^{\circ} \mathrm{C}\right)$ (ice bath), and then graphite $(2 \mathrm{~g})$ and $\mathrm{KMnO}_{4}(6 \mathrm{~g})$ were added slowly. After an increase in temperature to $35^{\circ} \mathrm{C}\left( \pm 2^{\circ} \mathrm{C}\right)$, the mixture was stirred by a magnetic stirring bar and mixed for three different time periods: 2, 4, and $6 \mathrm{~h}$. Later, the excess water was incorporated into the mixture and $\mathrm{H}_{2} \mathrm{O}_{2}(10 \mathrm{~mL})$ was added until there was no gas production.

Filtration was performed with distilled water in a glass filter, and the obtained brown GO was dried in an oven (Barnstead Thermolyne, Model 3478) at $65^{\circ} \mathrm{C}$ for $12 \mathrm{~h}$.

Then, a solution containing $100 \mathrm{mg}$ of dried GO in $10 \mathrm{~mL}$ of $\mathrm{H}_{2} \mathrm{O}$ was prepared. This solution was sonicated for $3 \mathrm{~h}$ at room temperature with the aid of an ultrasonic bath (Branson 1510R-MTH) in two different degassing units (55 and 65). The modification in degassing could contribute to changing the amount of functional groups in the graphene oxide obtained and in the sheets numbers, thereby promoting changes in their physical and structural features of graphene oxide sheets (GEO).

2.2. Graphene Oxide Samples. The designation of the graphite oxide samples (GO) is GO-2, GO-4, and GO-6, in which the number after the acronym means the time in hours of GO oxidation reaction. For the graphene oxide samples, the designation is GEO-2-55, GEO-2-65, GEO-4-55, GEO-4-65, GEO-6-55, and GEO-6-65. The first number also indicates the oxidation time in hours from GO, and the second number (55 and 65) indicates the degassing in the ultrasonic bath.

2.3. Photocatalytic Test. Photocatalytic and photolysis experiments were conducted in a batch photoreactor. The smallscale photoreactor system consisted of a Pyrex glass flask with a capacity of $250 \mathrm{~mL}$. The glass flask reactor was filled with $100 \mathrm{~mL}$ of an aqueous solution containing phenol (100 ppm). The $\mathrm{pH}$ of the solution was neutral. The temperature of the reactor was maintained at room temperature and the suspension was magnetically stirred. The experiments were performed with $2 \mathrm{~h}$ of UV light irradiation, following the methodology for phenol determination (ASTM-D1783-0). The percentage values of phenol removal were determined by taking aliquots at the beginning and end of the reaction time. The solution was irradiated with a UV-vis lamp at $254 \mathrm{~nm}$ and 10 and $20 \mathrm{mg}$ of graphite oxide and graphene oxide were used in the photocatalytic test. The absorption of the samples was analyzed using a UV-vis spectrophotometer (Spectronic Genesys 2PC) at $510 \mathrm{~nm}$. Oxides of graphite 
and graphene were removed by filtration. Also, in the same reactor under similar conditions but without UV light, the absorption test was performed for GEO-2-55 and GEO-265. Each experiment was performed in at least triplicate under identical conditions. After each reaction, the resulting solution was poured into a fine filter and the filtered solution graphitic material phenol is separated and sheltered in a container. The carbon nanomaterials used also could be reutilized if desorption process is realized, research related with the number of reuses of this carbon nanomaterials, could be done in the future to meet the functionality as reusable photocatalyst.

2.4. Characterization. Fourier transform infrared spectroscopy (FT-IR) studies were performed using a Bruker-Vector 33 with a scanning range of $4000-500 \mathrm{~cm}^{-1}$ with resolution of $4 \mathrm{~cm}^{-1}$. The test samples were pressed into $\mathrm{KBr}$ tablets and all samples were prepared with the same ratio of $\mathrm{KBr}$-graphitic materials. Micro-Raman (Dilor, Lab Ram) measurements were carried out at $488 \mathrm{~nm}$ incident laser light with a spectral resolution of $1 \mathrm{~cm}^{-1}$. The physical morphology of graphene oxide sheets was analyzed by transmission electron microscopy (TEM), using a JEOL-1010 microscope operated to $80 \mathrm{kV}$. UV-vis spectroscopy (Spectronic Genesys 2PC with wavelength of 200 to $1000 \mathrm{~nm}$ ) was used to assess the chromophores present in the graphitic materials and to determine the band gap, the samples were prepared in aqueous solution, and a quartz cell of $3 \mathrm{~mL}$ was used for analysis.

\section{Results and Discussion}

3.1. FT-IR Spectroscopy. Figure 1 shows the FT-IR spectra of GEO and GO; the band at $1730 \mathrm{~cm}^{-1}$ is attributed to carboxyl groups $\nu(\mathrm{C}=\mathrm{O})$. The peak around $1619 \mathrm{~cm}^{-1}$ corresponds to the stretching band $v(\mathrm{C}=\mathrm{C})$. The peaks at $1020-1090 \mathrm{~cm}^{-1}$ are attributed to the $\mathrm{C}-\mathrm{O}-\mathrm{C}, \mathrm{C}-\mathrm{O}$, and $\mathrm{C}-\mathrm{OH}$ bands, giving evidence for the presence of oxygen-containing groups, caused by the chemical oxidation reaction [8, 14, 37]. All spectra show these characteristic bands reported for graphite and graphene oxides. The band corresponding to $v(\mathrm{C}=\mathrm{O})$ at $1730 \mathrm{~cm}^{-1}$ shows a decrement in the spectra related with GEO obtained at 65 degassing units. In the same spectra appear the band at $1690 \mathrm{~cm}^{-1}$ and also a clear increment in the band around $1410 \mathrm{~cm}^{-1}$; these two signals indicate that more degassing units produce carboxylate groups [38]. The signals related to $\nu(\mathrm{C}=\mathrm{O})$ and $\mathrm{C}-\mathrm{O}-\mathrm{C}, \mathrm{C}-\mathrm{O}$, and $\mathrm{C}-\mathrm{OH}$ are more intense in the GO-4 and GO-2 spectra than in the GO6 spectrum, indicating that longer oxidation does not necessarily produce a larger amount of functional groups in GO. In the same figure, the bands related to the oxidation process $(\mathrm{C}=\mathrm{O}, \mathrm{C}-\mathrm{O}-\mathrm{C}, \mathrm{C}-\mathrm{O}$, and $\mathrm{C}-\mathrm{OH})$ show clear differences with greater intensity in the spectra of GEO when 55 units of degassing were used (GEO-2-55, GEO-4-55, and GEO-6-55) in comparison with the spectra of the samples treated with 65 units of degassing (GEO-2-65, GEO-4-65, and GEO-6-65). In addition, the spectra of GEO exposed to 65 units of degassing show the peak around $1645 \mathrm{~cm}^{-1}$ attributed to $\nu(\mathrm{C}=\mathrm{O})$ related to ketones, and also the bands at $1690 \mathrm{~cm}^{-1}$ have been related

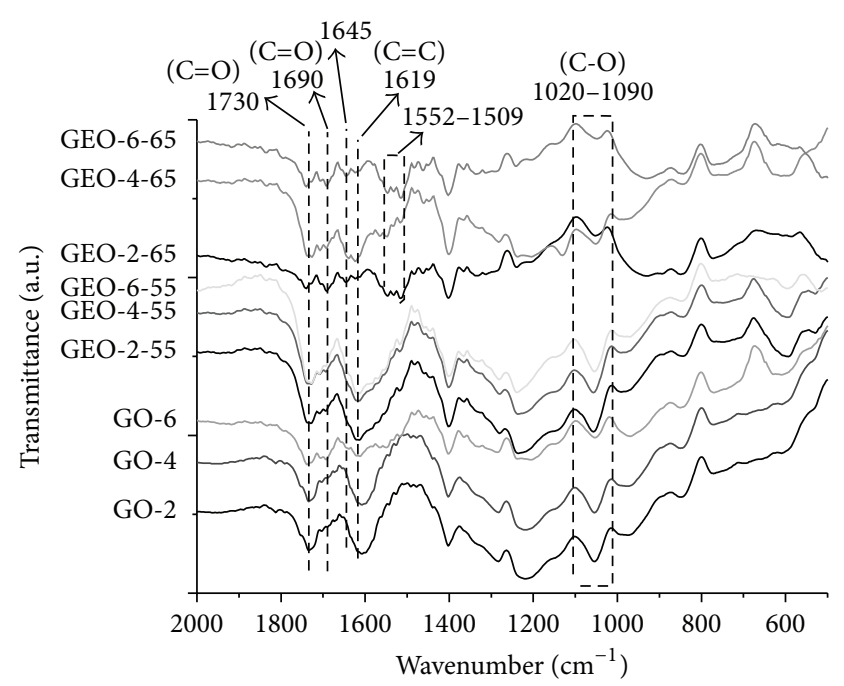

Figure 1: FT-IR spectra of GO-2, GO-4, GO-6, GEO-2-55, GEO-455, GEO-6-55, GEO-2-65, GEO-4-65, and GEO-6-65.

with quinone groups $[2,38]$. These signals are not presented in the spectra of GEO exposed to 55 units of degassing; this fact, together with the bands only presented in the spectra of the samples treated to 65 units of degassing, located around $1552 \mathrm{~cm}^{-1}$ to $1509 \mathrm{~cm}^{-1}$ and assigned to unoxidized graphitic domains [39], corroborates the notable changes in the GEO samples due to the degassing action of the ultrasonic bath. This effect can be attributed to the cavitation effect which generates increased outgassing; this effect is stronger with 65 units than with 55 units of degasification, leading to the elimination of oxygenated functional groups present in the graphite oxide.

3.2. Raman Spectroscopy. Raman spectroscopy is a widely used tool for the characterization of carbon products, especially considering conjugated and double carbon-carbon bonds. The Raman spectra of GO are shown in Figure 2(a) and for GEO in Figure 2(b). The graphitic materials show different peaks; the $\mathrm{D}$ band located around $1356 \mathrm{~cm}^{-1}$ is due to the out-of-plane breathing mode of $\mathrm{sp}^{2}$ atoms and is active in the presence of defects, whereas $2 \mathrm{D}$ (around $2680 \mathrm{~cm}^{-1}$ ) is the second order of this vibrational mode $[5,6]$. The tangential $G$ mode at $1593 \mathrm{~cm}^{-1}$ corresponds to the first-order scattering of the E2g mode in-phase vibration of the graphite lattice. In the same way, the intensity and broadness of the 2D band in graphene is a function of the number of layers. This band is a second-order process related to a phonon near the $\mathrm{K}$ point in graphene, activated by double resonance processes, which are responsible for its dispersive nature and cause a strong dependence on any perturbation to the electronic and/or phonon structure of graphene. Thus, the $2 \mathrm{D}$ band is very important for characterizing specific $\mathrm{sp}^{2}$ nanocarbons $[6,7,14,37]$. The ratio of the intensities of the $D$ and $G$ bands (ID/IG) is often used as a means of determining the number of layers in a graphene sample and its overall stacking behavior; high D/G ratios indicate a high degree of exfoliation 


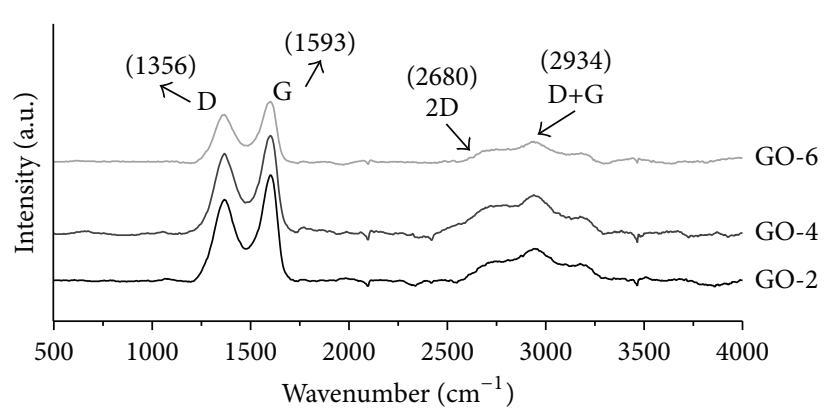

(a)

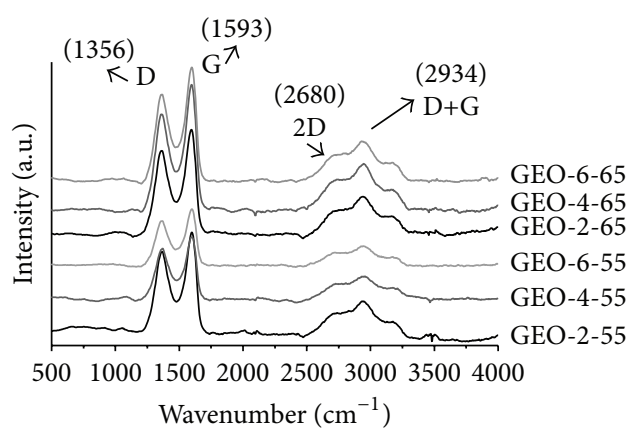

(b)

FIGURE 2: Raman spectra of (a) GO-2, GO-4, and GO-6 and (b) GEO-2-55, GEO-4-55, GEO-6-55, GEO-2-65, GEO-4-65, and GEO-6-65.

disorder. Changes in the Raman spectra occur due to changes in the number of layers or due to doping and reflect the evolution of the electronic structure and electron-phonon interactions [40]. Consequently, changes in the 2D band in graphene oxide are related to considerable defects in the graphene sheet, produced by oxidation [41]. In the Raman spectra (Figure 2(a)) of GO-2, GO-4, and GO-6, it can be seen that the $\mathrm{D}, \mathrm{G}, 2 \mathrm{D}$, and $\mathrm{D}+\mathrm{G}$ bands (at $1356 \mathrm{~cm}^{-1}, 1593 \mathrm{~cm}^{-1}$, $2680 \mathrm{~cm}^{-1}$, and $2934 \mathrm{~cm}^{-1}$, resp.) are very similar in terms of intensity and width for GO-2 and GO-4 but dissimilar in comparison with the GO-6 spectrum, where the three bands decrease in intensity. Also in the Raman spectra all samples show the $\mathrm{D}+\mathrm{G}$ band which is a combination band related with the concentration of defects due to the present oxygenated groups $[42,43]$.

The ID/IG ratio (Table 1) was lower in GO-6 than in GO4. Thus, in $6 \mathrm{~h}$ of reaction to oxidize graphite, apparently more oxygen-containing functional groups were not generated. This also agrees with the bands analyzed by infrared spectroscopy. Table 1 includes all the values for the ID/IG ratios. Conversely, the ratio obtained for ID/IG decreased for the GEO samples obtained with 65 degassing units, in comparison with GEO treated at 55 units; thus, it can be concluded that sheets with less oxygenated groups were obtained with 65 units in comparison with sheets obtained at 55 units, due to degassing effect.

3.3. Transmission Electron Microscopy. In Figure 3(a), the sheets obtained for GEO-2-55 are shown. The characteristic roughness of graphene sheets is observed, including transparency and uniformity in the morphology. Figure 3(b) shows sheets of GEO-4-55, which are less corrugated than GEO-2-55, but similar in transparency although more stacked. Figure 3(c) shows GEO-6-55 materials, and the sheets tend to be in shades of gray, depending on the number of overlapping layers of carbon; it is important to mention that the formation of a layer or multilayer is not a factor controlled by chemical method. Thus, Raman and FT-IR characterizations show a clear evidence that graphite and graphene oxides are obtained, and also, the morphology obtained by TEM is considered acceptable and useful to this research. For the GEO sheets treated at 65 degassing units,
TABLE 1: ID/IG and IG/ID ratio values in the Raman spectra.

\begin{tabular}{lc}
\hline Sample & ID/IG \\
\hline GO-2 & 0.67 \\
GO-4 & 0.71 \\
GO-6 & 0.68 \\
GEO-2-55 & 0.75 \\
GEO-4-55 & 0.74 \\
GEO-6-55 & 0.72 \\
GEO-2-65 & 0.7 \\
GEO-4-65 & 0.65 \\
GEO-6-65 & 0.66 \\
\hline
\end{tabular}

less corrugated surface is observed in GEO-4-65 and GEO6-65 (Figures 3(e) and 3(f)) than in the samples obtained with degassing at 55 units, but the irregular shape of the sheets is similar to that obtained for GEO treated at 55 units. Figure 3(d) shows the micrograph obtained from sheets of GEO-2-65, which are very similar to GEO-2-55 sheets in transparency and roughness and unlike the sheets of GEO4-65 (Figure 3(e)) have more transparency, indicating less carbon layers. Finally in the sheets of GEO-6-65 (Figure 3(f)), clear folds at the ends of these layers are found; although the transparencies as well as shape are very similar to the other sheets, these sheets are stacked. It is important to mention that, in a previous work reported, the average value of the thickness of this kind of GEO was $0.56 \mathrm{~nm}$ obtained by atomic force microscopy (AFM). According to the thickness, GEO should not exceed 3 or 4 overlapping leaves [37]. And in the case of graphite oxide (GO), it is known that the thickness value is in the order of microns.

Thus, the morphology of GEO is apparently not modified in general as a factor of degassing units, and only the roughness and stacking were affected by oxidation time. So, the samples treated for $2 \mathrm{~h}$ independently of degassing units are the most rough (Figures $3(\mathrm{a})$ and $3(\mathrm{~d})$ ); $4 \mathrm{~h}$ of oxidation time produces smoother sheets (Figures $3(\mathrm{~b})$ and 3(e)). However, if a longer oxidation time was used ( $6 \mathrm{~h}$ ), the surface is not modified in relation to the samples treated for $4 \mathrm{~h}$, but more stacking is found in these sheets (Figures 3(c) and 3(f)). 


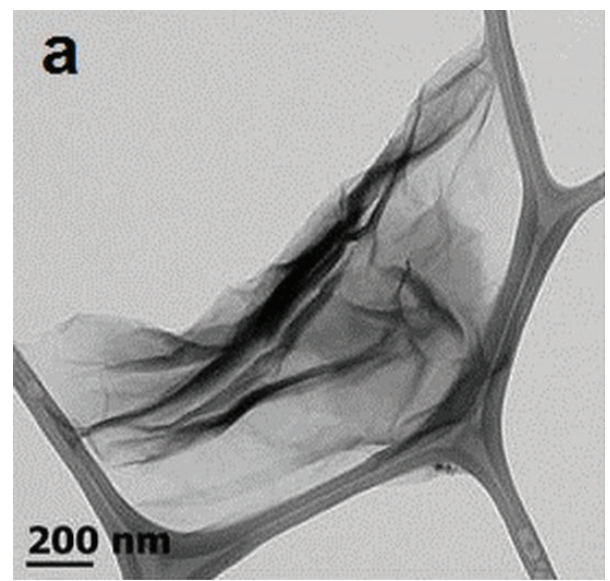

(a)

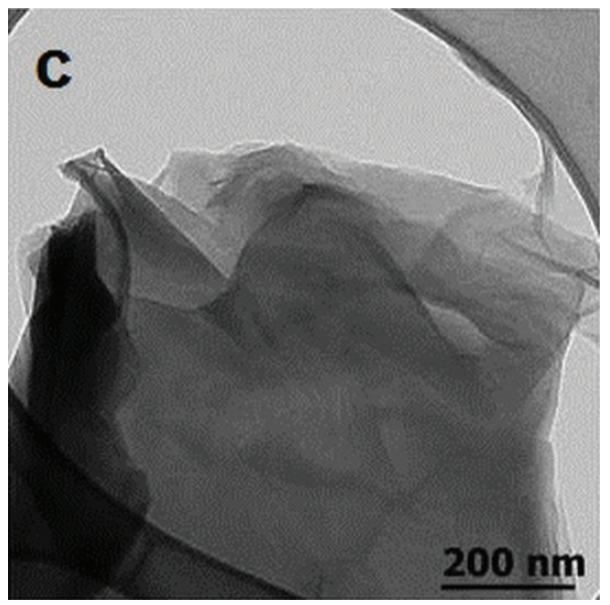

(c)

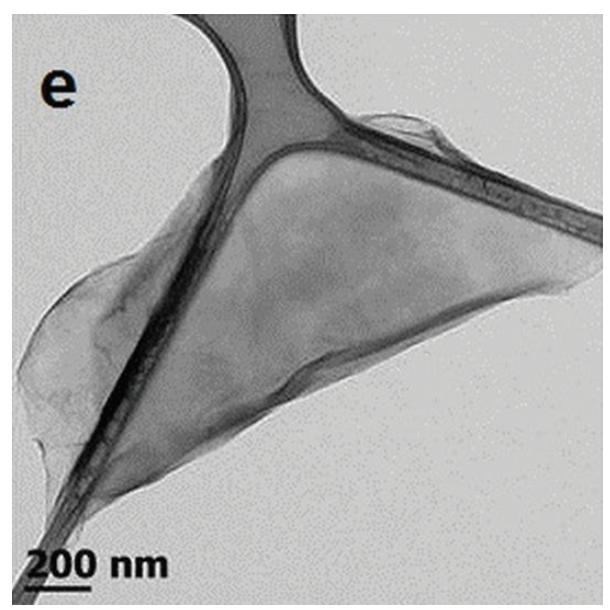

(e)

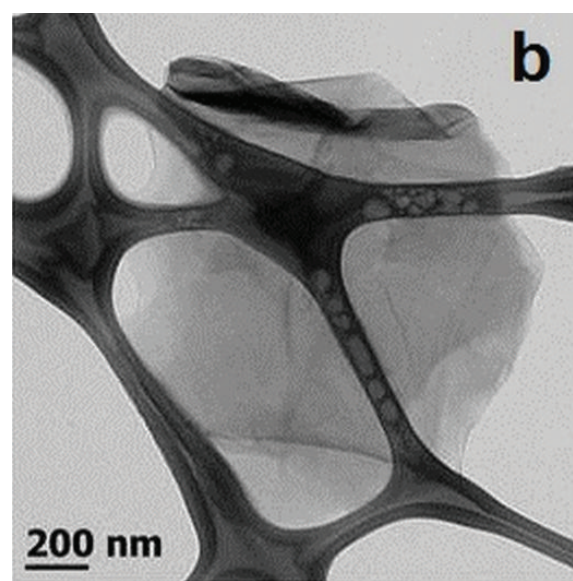

(b)

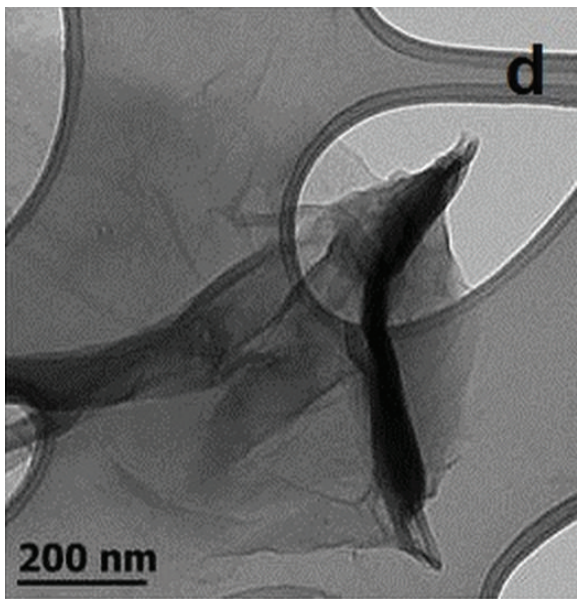

(d)

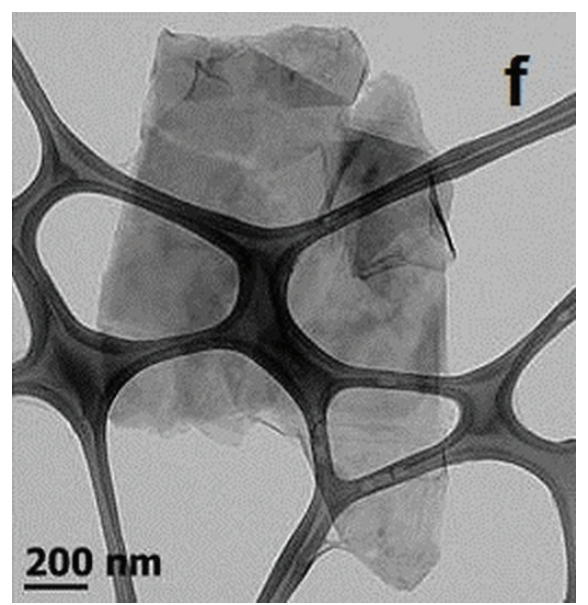

(f)

Figure 3: TEM micrographs of (a) GEO-2-55, (b) GEO-4-55, (c) GEO-6-55, (d) GEO-2-65, (e) GEO-4-65, and (f) GEO-6-65.

3.4. UV-Vis Spectroscopy. The UV-vis spectra (Figure 4) exhibit two characteristic absorption bands for graphite oxide (GO) and graphene oxide (GEO), with a maximum at $228 \mathrm{~nm}$, corresponding to the $\pi-\pi^{*}$ transitions of aromatic $\mathrm{C}=\mathrm{C}$ and $\mathrm{C}-\mathrm{C}$ bonds; the shoulder at $\sim 300 \mathrm{~nm}$ is ascribed to the $n-\pi^{*}$ transitions of $\mathrm{C}=\mathrm{O}$ bonds $[27,35,36]$. These bands are presented specifically with the incidence of ultraviolet light in graphitic materials and in the GO and GEO samples of this research are clearly defined. Thus, the values of the band gap are calculated based on these spectra. 


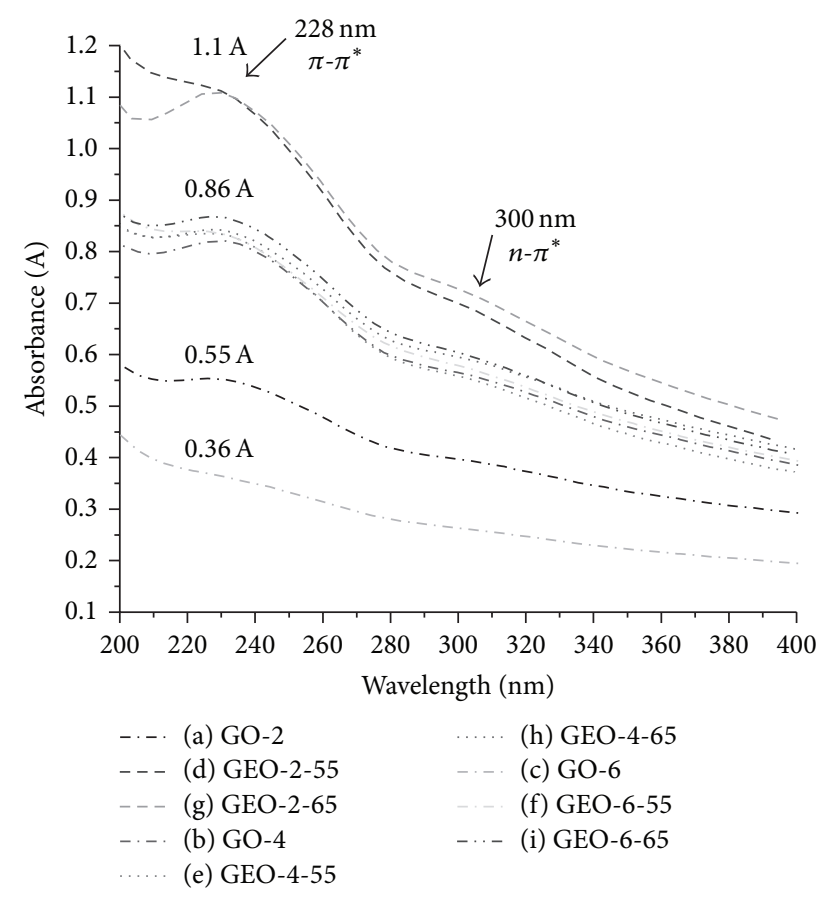

FIgUre 4: UV-vis spectra of (a) GO-2, (b) GO-4, (c) GO-6, (d) GEO2-55, (e) GEO-4-55, (f) GEO-6-55, (g) GEO-2-65, (h) GEO-4-65, and (i) GEO-6-65.

Band gap values were determined from Tauc's plot of $(\alpha h \nu)_{2}$ versus photon energy $(h \nu)$, using the UV-vis spectra wherein the absorption coefficient varies as a function of frequency, according to $\alpha h v \&\left(h v-E_{g}\right)_{n}$, where $h v$ is the photon energy and $E_{g}$ is the band gap; $n=2$ for indirect transitions (I) and $n=1 / 2$ for direct transitions (D) $[2,27,37$, as shown in Table 2. Also in Figure 5 is shown a graph for the value obtained in GEO-2-55 specifically. The indirect band gap values correspond to small values, because the absorption band is not specified, but there are areas with lower activity and thus the chart detects even the slightest intersection giving a small band gap value, indicating that certain spaces in the graphitic materials have less separation of the valence and conduction bands.

3.5. Photocatalysis Test. To determine the photocatalytic effect of GEO-2-55, adsorption and photolysis tests were performed (see the results in Table 3). The aim was to confirm that this material was not effective as an absorbent material, because the percentage of phenol removal was almost nil, indicating that it was not able to absorb phenol molecules. However, we observed that $7 \%$ of phenol is removed from water by photolysis. Photolysis is a technique that is not used alone, and although the encapsulated air in the reactor and incident UV light generate oxidizing radicals able to degrade phenol in water, these are not able to achieve a high degradation percentage $[44,45]$.

Table 4 shows a summary of photocatalytic probe using different samples of GO and GEO. With $200 \mathrm{mg} / \mathrm{L}$ of graphitic material in the photocatalytic process, the increase in
TABLE 2: Band gap values $\left(E_{g}\right)$, indirect (I) and direct (D), obtained through spectra of UV-vis for all samples of GO and GEO.

\begin{tabular}{lcc}
\hline Sample & $E_{g}(\mathrm{I}) \mathrm{eV}$ & $E_{g}(\mathrm{D}) \mathrm{eV}$ \\
\hline GO2 & 2.80 & 4.70 \\
GO4 & 1.94 & 4.90 \\
GO6 & 1.90 & 3.96 \\
GEO-2-55 & 1.87 & 4.04 \\
GEO-4-55 & 1.89 & 4.1 \\
GEO-6-55 & 1.89 & 4.07 \\
GEO-2-65 & 1.5 & 4.0 \\
GEO-4-65 & 2.05 & 4.6 \\
GEO-6-65 & 2.1 & 4.0 \\
\hline
\end{tabular}

TABLE 3: Removal percentage of phenol in water by absorption test using GEO-2-55 and GEO-2-65 and in the photolysis test.

\begin{tabular}{lc}
\hline & Absorption for 2 $\mathrm{h}$ \\
Absorbent & Removal percentage \\
\hline GEO-2-55 (100 mg) & $0 \%$ \\
GEO-2-55 (200 mg) & $1 \%$ \\
GEO-2-65 (100 mg) & $0 \%$ \\
GEO-2-65 (200 mg) & $0 \%$ \\
\hline \multicolumn{2}{c}{ Photolysis (UV-254 $\mathrm{nm})$ for 2 $\mathrm{h}$} \\
Phenol solution & Removal percentage \\
\hline $100 \mathrm{ppm}$ & $7 \%$ \\
\hline
\end{tabular}

the percentage of phenol degradation in water is improved in the case of GEO-2-55, GEO-4-55, and GEO-6-55. The increase in degradation is minimal when the probes are used at $200 \mathrm{mg} / \mathrm{L}$ rather than $100 \mathrm{mg} / \mathrm{L}$ for almost all samples. When the amount of catalysts is duplicated, the increase in the degradation percentage of phenol is around $1 \%$ in the majority of probes, with the exception of GEO obtained with 55 units of degassing (GEO-2-55, GEO-4-55, and GEO-6-55).

As mentioned before, the photocatalytic activity of GO and GEO has been verified using different probes [19-28] but any for eliminating phenol in water. Thus, the results indicate that the minimal degradation of phenol obtained using GO is due to the dimensions of the graphite oxide (3D), since a greater number of graphite layers allow less interaction between oxygenated functional groups $(\mathrm{C}=\mathrm{O}, \mathrm{C}-\mathrm{O}$, and $\mathrm{O}$ $\mathrm{H}$ ) on the graphite surface with phenol molecules, such that the photocatalytic process is impaired.

In the case of the samples of GEO-2-65, GEO-4-65, and GEO-6-65, the low percentage of degradation is attributed to the nature of the samples, which contained fewer functional groups at the surface as they are eliminated by the degassing process in the ultrasonic bath (this is demonstrated in an earlier section). It is clear that oxygenated groups play an important role in generating oxidizing radicals (such as $\mathrm{OH}$ or $\mathrm{O}^{*}$ ) in photocatalytic probes. It is assumed that the effect in removal that is generated in the photolysis is not completely reflected in photocatalysis, because graphitic material in the solution of phenol modifies the interaction of UV radiation with the solution, and then, the effect of radiation is not 
TABLE 4: Removal percentage of phenol in water in the photocatalytic test using GO and GEO.

\begin{tabular}{|c|c|c|c|c|c|}
\hline Photocatalysts (10 mg) & $\begin{array}{c}\text { Removal percentage of } \\
\text { phenol solution }\end{array}$ & Error (\%) & Photocatalysts (20 mg) & $\begin{array}{c}\text { Removal percentage of } \\
\text { phenol solution }\end{array}$ & Error (\%) \\
\hline GO-2 & $5.05 \%$ & \pm 0.1 & GO-2 & $7.89 \%$ & \pm 0.1 \\
\hline GO-4 & $3.89 \%$ & \pm 0.1 & GO-4 & $4.81 \%$ & \pm 0.08 \\
\hline GO-6 & $6.43 \%$ & \pm 0.05 & GO-6 & $7.89 \%$ & \pm 0.08 \\
\hline GEO-2-55 & $12.11 \%$ & \pm 0.05 & GEO-2-55 & $38.62 \%$ & \pm 0.1 \\
\hline GEO-4-55 & $4.90 \%$ & \pm 0.15 & GEO-4-55 & $12.29 \%$ & \pm 0.1 \\
\hline GEO-6-55 & $6.32 \%$ & \pm 0.05 & GEO-6-55 & $14.96 \%$ & \pm 0.08 \\
\hline GEO-2-65 & $3.45 \%$ & \pm 0.1 & GEO-2-65 & $5.86 \%$ & \pm 0.06 \\
\hline GEO-4-65 & $2.84 \%$ & \pm 0.05 & GEO-4-65 & $4.86 \%$ & \pm 0.08 \\
\hline GEO-6-65 & $3.87 \%$ & \pm 0.15 & GEO-6-65 & $5.05 \%$ & \pm 0.12 \\
\hline
\end{tabular}
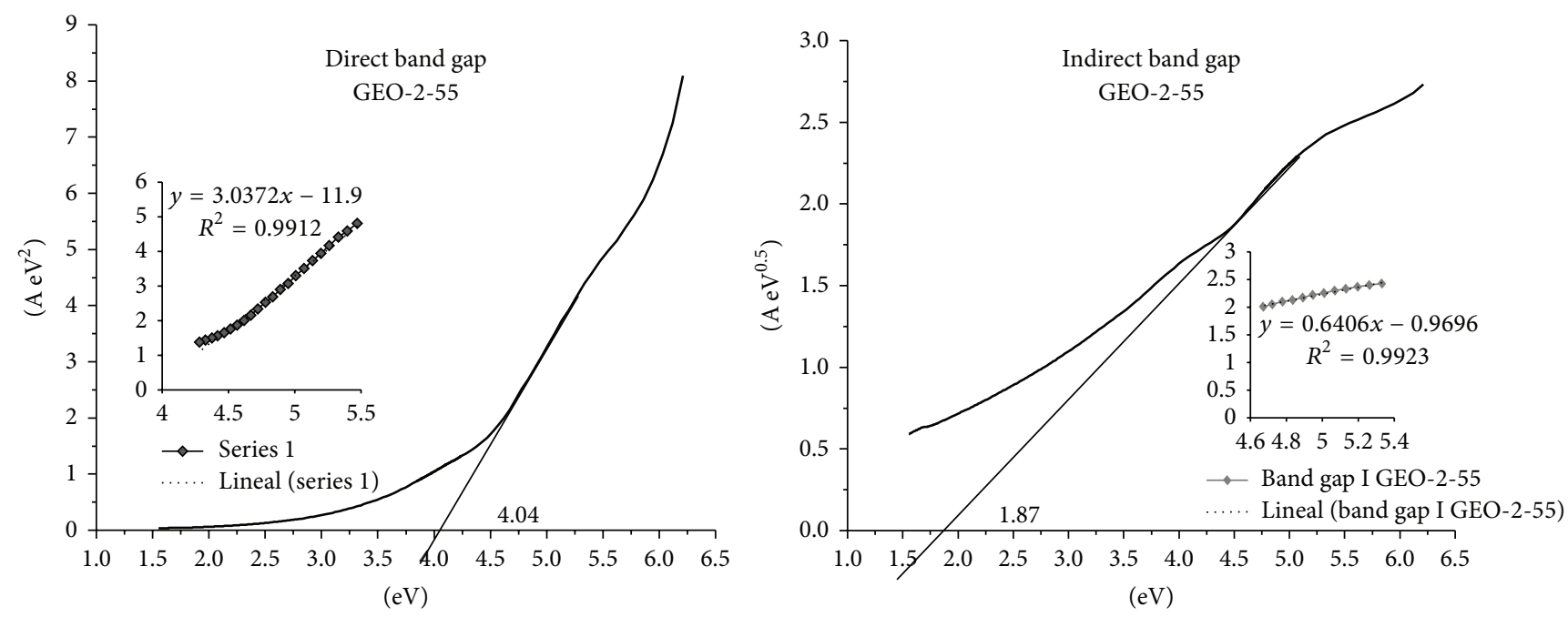

FIGURE 5: Determination of direct and indirect band gap from Tauc's plot of $(\alpha h \nu)_{2}$ versus photon energy $(h \nu)$, for GEO-2-55.

exactly the same, in spite of the encapsulated air, because the photocatalyst plays a prominent role.

New materials have been tested in the removal of phenol by means of photocatalysis, not just carbon materials, in previous section in this paper, such as Nano ZnO [29], $\mathrm{CeO}_{2} / \mathrm{MgAl}$ layered double hydroxides [30], and GRO$\mathrm{TiO}_{2}$ nanocomposites [31], and these photocatalytic materials remove 80,50 , and $90 \%$ of phenol, respectively. Additionally, photocatalytic activity by graphene oxide (GEO) composite materials has been reported, for instance, $\mathrm{TiO}_{2}$-graphene oxide [46] and, more recently, BiOI-GO (graphene oxide) composite [47] and GO/PPy (graphene oxide/polypyrrole) [48]; these materials remove around $90 \%$ of phenol. However, the application of pure graphite materials as photocatalysts materials has been investigated minimally $[49,50]$, generating great expectation to investigate the photocatalytic effectiveness individually in the removal of pollutants in water. Thus, the $38 \%$ of removed phenol is low compared with the percentage of other materials mentioned. However, the aim to evaluate the effectiveness of photocatalyst of GEO-255 opens a field to apply these materials without doping in the removal of organic pollutants and diversify its potential as a photocatalyst material. Nevertheless, the most important aspect of this study is understanding the parameters that play an important role in carbon material preparation, specifically in this research with a focus on photocatalytic activity without other materials. Also, if the amount of catalyst material that is used in this research is considered, the removal of phenol in water achieved, that is, $38 \%, 12 \%$, and $15 \%$, using GEO-2-55, GEO-4-55, and GEO-6-55, respectively, could be significant. The removal percentage of phenol is almost proportional to the increase in the photocatalytic effect for these samples (GEO treated with 55 degassing units; see Table 4). Thus, these results open up the range of possible applications of graphene oxide as a photocatalytic material by considering the processing conditions. Also, it might assume good semiconductor capabilities for these GEO materials, which could be activated with UV light at $\lambda=254 \mathrm{~nm}$; this positively affected the reaction rate of catalysis process and therefore promoted the degradation percentage of phenol present in water. This indicates that GEO-55, especially GEO2-55, may be a good material for use as a photocatalyst in heterogeneous photocatalysis. Also, to complement the results, the sample that shows the best removal percentage 


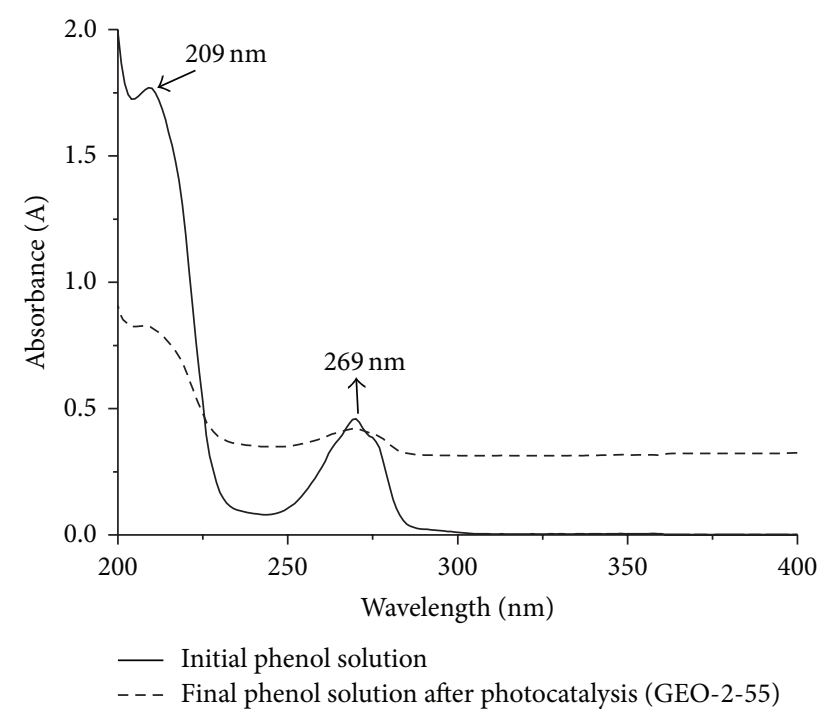

FIGURE 6: UV-vis spectra of photocatalytic test for phenol solution using GEO-2-55, in the initial and final of reaction ( $2 \mathrm{hr})$.

was characterized by UV-vis spectroscopy. The spectra of initial and final solution of phenol used in the photocatalytic reaction with GEO-2-55 are shown in Figure 6; the results show a clear reduction in the characteristic absorption bands of phenol after photocatalytic process performed.

\section{Conclusion}

Oxygen functional groups generated in graphitic sheets do not increase linearly with chemical oxidation time in graphite oxide; only some morphological changes are observed in terms of stacking and roughness with variation in this parameter. However, in obtaining graphene oxide using an ultrasonic bath with degassing, modification of the other parameter produces changes in the graphene oxide sheets. This removes oxygenated functional groups and affects the photocatalytic activity of graphene oxide. Although the band gap values are in the same range, oxygenated functional groups appear to play an important role. On the other hand, the number of layers and therefore dimensionality are also a factor affecting photocatalytic activity in this case and led to a difference between the effectiveness of graphite oxide and graphene oxide. It is found that GEO-2-55 is the graphitic nanometric material that presents the best photocatalytic activity. The combination of oxygenated functional groups, the band gap range (1.8-4 eV), and the roughness in the sheet are more efficient with the incidence of UV light at $254 \mathrm{~nm}$ than only photolysis or adsorption process.

The removal of $38 \%$ of the phenol in water with GEO2-55 is a very favorable result and makes this material viable and efficient for applications in alternative advanced oxidation processes. GEO-2-55 shows photocatalytic activity with the incidence of UV light and can be considered as a photocatalytic material capable of degrading organic pollutants present in water. Results presented here could be as starting point to get chemical and physical structural changes in this kind of carbon materials using single changes in processing conditions and then understand the principles of graphitic materials, to get better performance as photocatalyst to remove some pollutants from water or other typical applications of photocatalysis.

\section{Conflict of Interests}

The authors declare that there is no conflict of interests regarding the publication of this paper.

\section{Acknowledgments}

The authors thank Ms. Maria de Lourdes Palma Tirado, Instituto de Neurobiologia, UNAM, for her assistance with TEM. Thanks are also due to CINVESTAV Querétaro, particularly to Dr. Sergio Jimenez and Mr. Francisco Rodriguez for their assistance with micro-Raman spectroscopy. This paper is in memoriam Dr. Adolfo M. Espíndola-González (1977-2014).

\section{References}

[1] M. Seredych, R. Pietrzak, and T. J. Bandosz, "Role of graphite oxide (GO) and polyaniline (PANI) in $\mathrm{NO}_{2}$ reduction on GO-PANI composites,' Industrial and Engineering Chemistry Research, vol. 46, no. 21, pp. 6925-6935, 2007.

[2] D. R. Dreyer, S. Park, C. W. Bielawski, and R. S. Ruoff, "The chemistry of graphene oxide," Chemical Society Reviews, vol. 39, no. 1, pp. 228-240, 2010.

[3] A. M. Herrera, A. A. Abdala, J. M. McAllister, A. I. Aksay, and K. R. Prud'homme, "Intercalation and stitching of graphite oxide with diaminoalkanes," Langmuir, vol. 23, pp. 10644-10649, 2007.

[4] B. Ö. Monkul, Graphite intercalation with fluoroanions by chemical and electrochemical methods [Ph.D. thesis], Oregon State University, Corvallis, Ore, USA, 2010.

[5] K. N. Kudin, B. Ozbas, H. C. Schniepp, R. K. Prud'homme, I. A. Aksay, and R. Car, "Raman spectra of graphite oxide and functionalized graphene sheets," Nano Letters, vol. 8, no. 1, pp. 36-41, 2008.

[6] C. Nethravathi and M. Rajamathi, "Chemically modified graphene sheets produced by the solvothermal reduction of colloidal dispersions of graphite oxide," Carbon, vol. 46, no. 14, pp. 1994-1998, 2008.

[7] A. B. Bourlinos, D. Gournis, D. Petridis, T. Szabó, A. Szeri, and I. Dékány, "Graphite oxide: chemical reduction to graphite and surface modification with primary aliphatic amines and amino acids," Langmuir, vol. 19, no. 15, pp. 6050-6055, 2003.

[8] D. C. Zangmeister, "Preparation and evaluation of graphite oxide reduced at $220^{\circ} \mathrm{C}$," Chemistry of Materials, vol. 22, no. 19, pp. 5625-5629, 2010.

[9] J. R. Potts, D. R. Dreyer, C. W. Bielawski, and R. S. Ruoff, "Graphene-based polymer nanocomposites," Polymer, vol. 52, no. 1, pp. 5-25, 2011.

[10] S. Park and S. R. Ruoff, "Chemical methods for the production of graphenes," Nature Nanotechnology, vol. 58, pp. 217-224, 2009.

[11] H. Huawen, C. K. A. Chan, H. Hong et al., "Multifunctional organically modified graphene with super-hydrophobicity," Nano Research, vol. 7, no. 3, pp. 418-433, 2014. 
[12] H. M. Maximilian, Graphite oxide and graphene oxide based electrode materials for electrochemical double layer capacitors [Ph.D. thesis], Technische Universität München, Munich, Germany, 2010.

[13] S. Stankovich, D. A. Dikin, R. D. Piner et al., "Synthesis of graphene-based nanosheets via chemical reduction of exfoliated graphite oxide," Carbon, vol. 45, no. 7, pp. 1558-1565, 2007.

[14] S. Park, J. An, R. D. Piner et al., "Aqueous suspension and characterization of chemically modified graphene sheets," Chemistry of Materials, vol. 20, no. 21, pp. 6592-6594, 2008.

[15] S. Stankovich, R. D. Piner, X. Chen, N. Wu, S. T. Nguyen, and R. S. Ruoff, "Stable aqueous dispersions of graphitic nanoplatelets via the reduction of exfoliated graphite oxide in the presence of poly(sodium 4-styrenesulfonate)," Journal of Materials Chemistry, vol. 16, no. 2, pp. 155-158, 2006.

[16] L. J. Cote, J. Kim, V. C. Tung, J. Luo, F. Kim, and J. Huang, "Graphene oxide as surfactant sheets," Pure and Applied Chemistry, vol. 83, no. 1, pp. 95-110, 2011.

[17] S. Gurunathan, J. W. Han, A. Abdal Dayem, V. Eppakayala, and J.-H. Kim, "Oxidative stress-mediated antibacterial activity of graphene oxide and reduced graphene oxide in Pseudomonas aeruginosa," International Journal of Nanomedicine, vol. 7, pp. 5901-5914, 2012.

[18] A. Ciesielski and P. Samorì, "Graphene via sonication assisted liquid-phase exfoliation," Chemical Society Reviews, vol. 43, no. 1, pp. 381-398, 2014.

[19] T.-F. Yeh, J.-M. Syu, C. Cheng, T.-H. Chang, and H. Teng, "Graphite oxide as a photocatalyst for hydrogen production from water," Advanced Functional Materials, vol. 20, no. 14, pp. 2255-2262, 2010.

[20] T.-F. Yeh, F.-F. Chan, C.-T. Hsieh, and H. Teng, "Graphite oxide with different oxygenated levels for hydrogen and oxygen production from water under illumination: the band positions of graphite oxide," The Journal of Physical Chemistry C, vol. 115, no. 45, pp. 22587-22597, 2011.

[21] T.-F. Yeh, J. Cihlář, C.-Y. Chang, C. Cheng, and H. Teng, "Roles of graphene oxide in photocatalytic water splitting," Materials Today, vol. 16, no. 3, pp. 78-84, 2013.

[22] K. Krishnamoorthy, R. Mohan, and S.-J. Kim, "Graphene oxide as a photocatalytic material," Applied Physics Letters, vol. 98, no. 24, Article ID 244101, 2011.

[23] P. Shi, R. Su, S. Zhu, M. Zhu, D. Li, and S. Xu, "Supported cobalt oxide on graphene oxide: highly efficient catalysts for the removal of Orange II from water," Journal of Hazardous Materials, vol. 229-230, pp. 331-339, 2012.

[24] T. Jiang, Z. Tao, M. Ji, Q. Zhao, X. Fu, and H. Yin, "Preparation and photocatalytic property of $\mathrm{TiO}_{2}$-graphite oxide intercalated composite," Catalysis Communications, vol. 28, pp. 47-51, 2012.

[25] S. Vadivel, M. Vanitha, A. Muthukrishnaraj, and N. Balasubramanian, "Graphene oxide-BiOBr composite material as highly efficient photocatalyst for degradation of methylene blue and rhodamine-B dyes," Journal of Water Process Engineering, vol. 1, pp. 17-26, 2014.

[26] G. Hu and B. Tang, "Photocatalytic mechanism of graphene/titanate nanotubes photocatalyst under visible-light irradiation," Materials Chemistry and Physics, vol. 138, no. 2-3, pp. 608-614, 2013.

[27] J. Shen, N. Li, and M. Ye, "Supramolecular photocatalyst of RGO-cyclodextrin-TiO ${ }_{2}$," Journal of Alloys and Compounds, vol. 580, pp. 239-244, 2013.
[28] L. Guardia, S. Villar-Rodil, J. I. Paredes, R. Rozada, A. MartínezAlonso, and J. M. D. Tascón, "UV light exposure of aqueous graphene oxide suspensions to promote their direct reduction, formation of graphene-metal nanoparticle hybrids and dye degradation," Carbon, vol. 50, no. 3, pp. 1014-1024, 2012.

[29] K. Hayat, M. A. Gondal, M. M. Khaled, S. Ahmed, and A. M. Shemsi, "Nano ZnO synthesis by modified sol gel method and its application in heterogeneous photocatalytic removal of phenol from water," Applied Catalysis A: General, vol. 393, no. 1-2, pp. 122-129, 2011.

[30] J. S. Valente, F. Tzompantzi, and J. Prince, "Highly efficient photocatalytic elimination of phenol and chlorinated phenols by $\mathrm{CeO}_{2} / \mathrm{MgAl}$ layered double hydroxides," Applied Catalysis $\mathrm{B}$ : Environmental, vol. 102, no. 1-2, pp. 276-285, 2011.

[31] P. Wang, J. Wang, X. Wang et al., "One-step synthesis of easy-recycling $\mathrm{TiO}_{2}$-rGO nanocomposite photocatalysts with enhanced photocatalytic activity," Applied Catalysis B: Environmental, vol. 132-133, pp. 452-459, 2013.

[32] D. W. Lee and J. W. Seo, "Sp2/sp3 carbon ratio in graphite oxide with different preparation times," The Journal of Physical Chemistry C, vol. 115, no. 6, pp. 2705-2708, 2011.

[33] K. Krishnamoorthy, M. Veerapandian, K. Yun, and S.-J. Kim, "The chemical and structural analysis of graphene oxide with different degrees of oxidation," Carbon, vol. 53, pp. 38-49, 2013.

[34] T. Rattana, S. Chaiyakun, and P. Limsuwan, "Preparation and characterization of graphene oxide nanosheets," Procedia Engineering, vol. 32, pp. 759-764, 2012.

[35] G. I. Eskin, "Cavitation mechanism of ultrasonic melt degassing," Ultrasonics Sonochemistry, vol. 2, no. 2, pp. S137-S141, 1995.

[36] A. R. Jambrak, T. J. Mason, V. Lelas, Z. Herceg, and I. L. Herceg, "Effect of ultrasound treatment on solubility and foaming properties of whey protein suspensions," Journal of Food Engineering, vol. 86, no. 2, pp. 281-287, 2008.

[37] K. Bustos-Ramírez, A. L. Martínez-Hernández, G. MartínezBarrera, M. de Icaza, V. M. Castaño, and C. Velasco-Santos, "Covalently bonded chitosan on graphene oxide via redox reaction," Materials, vol. 6, no. 3, pp. 911-926, 2013.

[38] C. Jhon, "Interpretation of infrared spectra, a practical approach," in Encyclopedia of Analytical Chemistry, R. A. Meyer, Ed., pp. 10815-10837, John Wiley \& Sons Ltd, Chichester, UK, 2000.

[39] J. I. Parades, S. Villar-Rodil, A. Martínez-Alonso, and J. M. D. Tascón, "Graphene oxide dispersions in organic solvents," Langmuir, vol. 24, no. 19, pp. 10560-10564, 2008.

[40] C. N. R. Rao, K. Biswas, K. S. Subrahmanyam, and A. Govindaraj, "Graphene, the new nanocarbon," Journal of Materials Chemistry, vol. 19, no. 17, pp. 2457-2469, 2009.

[41] D. W. Lee and J. W. Seo, "Sp2/sp3 carbon ratio in graphite oxide with different preparation times," Journal of Physical Chemistry C, vol. 115, no. 6, pp. 2705-2708, 2011.

[42] L. Xu and L. Cheng, "Graphite oxide under high pressure: a Raman spectroscopic study," Journal of Nanomaterials, vol. 2013, Article ID 731875, 5 pages, 2013.

[43] I. Childres, L. A. Jaureguib, W. Parkb, H. Caoa, and Y. P. Chena, "Raman spectroscopy of graphene and related materials," in New Developments in Photon and Materials Research, J. I. Jang, Ed., pp. 1-20, Nova Science Publishers, Binghamton, NY, USA, 2013.

[44] K. Akin, I. Arslan-Alaton, O.-H. Tugba, and M. Bekbolet, "Degradation and detoxification of industrially important 
phenol derivatives in water by direct UV-C photolysis and $\mathrm{H}_{2} \mathrm{O}_{2}$ /UV-C process: a comparative study," Chemical Engineering Journal, vol. 224, no. 1, pp. 4-9, 2013.

[45] S. Ahmed, M. G. Rasul, W. N. Martens, R. Brown, and M. A. Hashib, "Heterogeneous photocatalytic degradation of phenols in wastewater: a review on current status and developments," Desalination, vol. 261, no. 1-2, pp. 3-18, 2010.

[46] T.-D. Nguyen-Phan, V. H. Pham, E. W. Shin et al., "The role of graphene oxide content on the adsorption-enhanced photocatalysis of titanium dioxide/graphene oxide composites," Chemical Engineering Journal, vol. 170, no. 1, pp. 226-232, 2011.

[47] R. Hea, S. Caoa, D. Guoa et al., "3D BiOI-GO composite with enhanced photocatalytic performance for phenol degradation under visible-light," Ceramics International, vol. 41, no. 3, part A, pp. 3511-3517, 2015.

[48] R. Hua, S. Daib, D. Shao, A. Alsaedi, B. Ahmad, and X. Wang, "Efficient removal of phenol and aniline from aqueous solutions using graphene oxide/polypyrrole composites," Journal of Molecular Liquids, vol. 203, pp. 80-89, 2015.

[49] J. S. Valente, F. Tzompantzi, J. Prince, J. G. H. Cortez, and R. Gomez, "Adsorption and photocatalytic degradation of phenol and 2,4 dichlorophenoxiacetic acid by $\mathrm{Mg}-\mathrm{Zn}-\mathrm{Al}$ layered double hydroxides," Applied Catalysis B: Environmental, vol. 90, no. 3-4, pp. 330-338, 2009.

[50] E. M. Seftel, M. C. Puscasu, M. Mertens, P. Cool, and G. Carja, "Assemblies of nanoparticles of $\mathrm{CeO}_{2}-\mathrm{ZnTi}-\mathrm{LDH}$ and their derived mixed oxides as novel photocatalytic systems for phenol degradation," Applied Catalysis B: Environmental, vol. 150-151, pp. 157-166, 2014. 

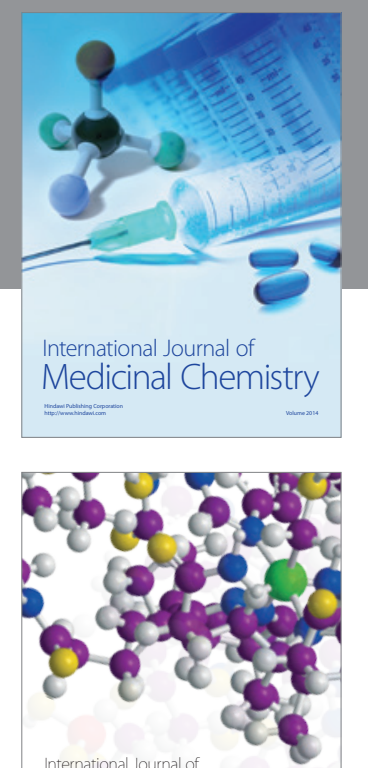

\section{Carbohydrate} Chemistry

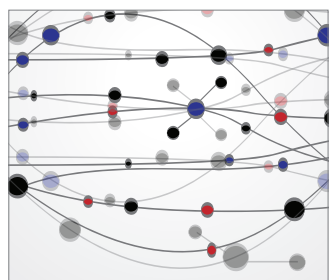

The Scientific World Journal
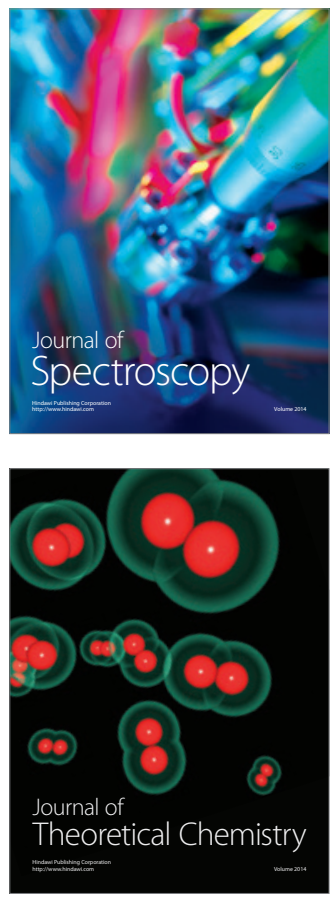
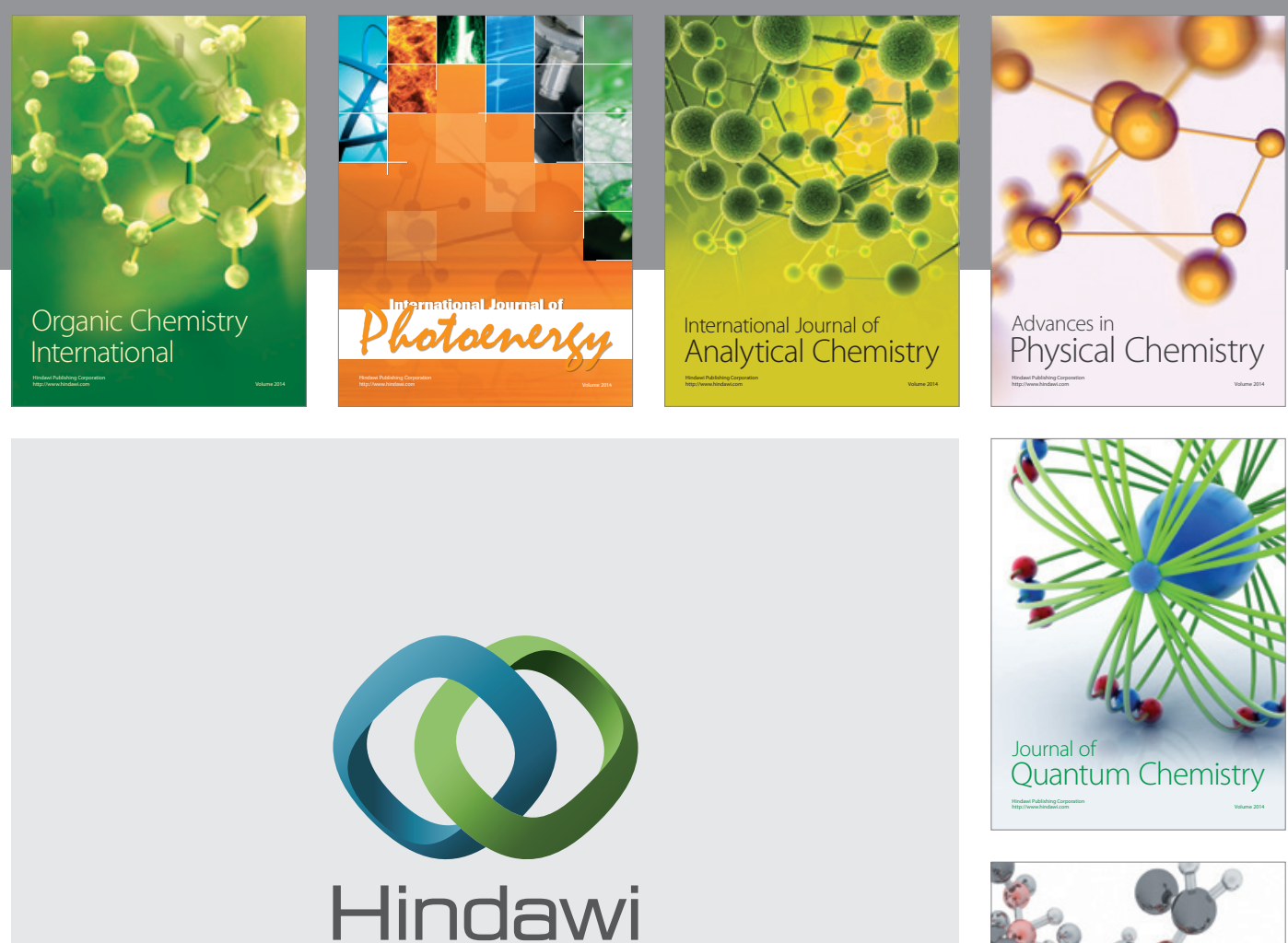

Submit your manuscripts at

http://www.hindawi.com

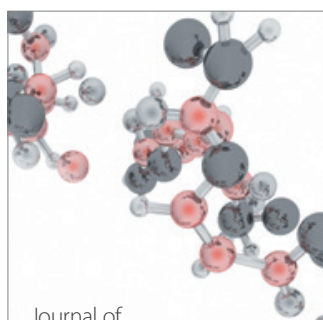

Analytical Methods

in Chemistry

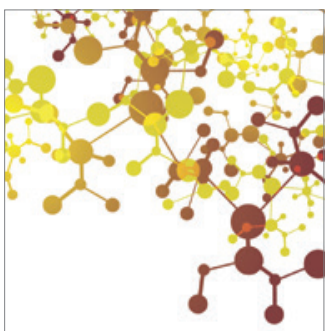

Journal of

Applied Chemistry

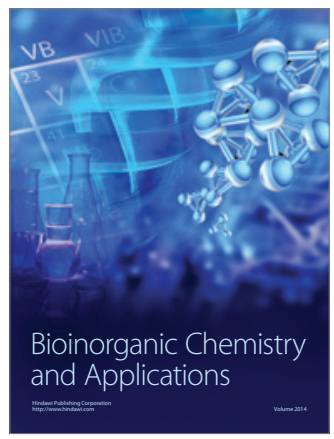

Inorganic Chemistry
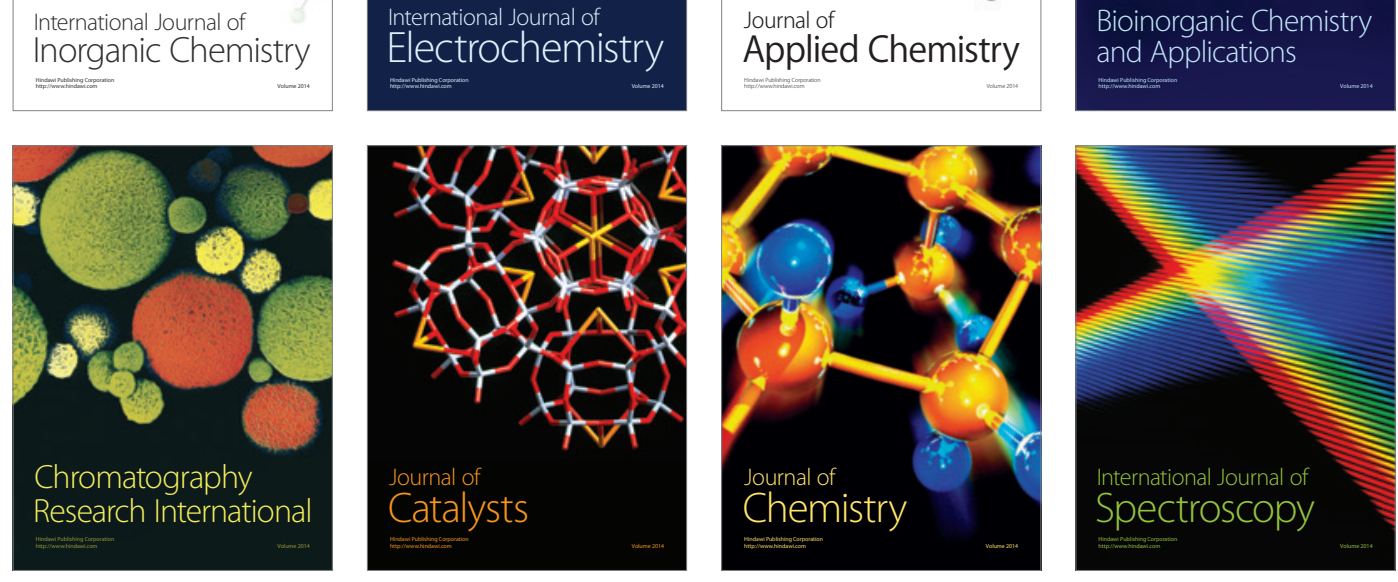